\title{
Caracterização granulométrica do sedimento de nascentes tropicais em áreas plantadas com eucalipto
}

\author{
Granulometric characterization of the sediment of tropical springs in eucalypt \\ plantation areas
}

\author{
Pedro Henrique Monteiro do Amaral ${ }^{\mathrm{I}}$, Sheila de Jesus Peixoto ${ }^{\mathrm{II}}$, \\ Micael Marlon de Moraes Machado ${ }^{\mathrm{III}}$, Cézar Henrique Barra Rocha ${ }^{\mathrm{IV}}$, \\ Roberto da Gama Alves ${ }^{v}$
}

\begin{abstract}
Resumo
Nascentes são afloramentos do lençol freático que formam fluxos de água importantes na prestação de serviços ecossistêmicos, como irrigação de florestas, fornecimento de água para o consumo humano e habitat para a biota aquática. No Brasil, áreas de Mata Atlântica estão sendo gradativamente substituídas por culturas de eucalipto, alterando, comumente, a composição do substrato das nascentes. O objetivo deste estudo foi verificar se a composição granulométrica do sedimento de nascentes em áreas de floresta difere de nascentes em áreas plantadas com eucalipto. A hipótese testada foi que nascentes em áreas de eucalipto apresentam diferenças na composição granulométrica e menor porcentagem de matéria orgânica quando comparadas com nascentes em áreas de floresta. Para tanto, foi coletado o sedimento de 20 nascentes, todas pertencentes à bacia do rio Paraíba do Sul, situadas no estado de Minas Gerais, Brasil. Foi possível observar que as nascentes em áreas de floresta estiveram associadas com areia muito grossa, enquanto que aquelas em área de eucalipto estiveram associadas a partículas de granulometria mais fina. Em relação à matéria orgânica, não foi observada diferença significativa entre as duas áreas. O estudo enfatiza a importância da vegetação ciliar para mitigar potenciais impactos da silvicultura do eucalipto no sedimento das nascentes.
\end{abstract}

Palavras-chave: Mata Atlântica; Silvicultura; Vegetação ciliar

\begin{abstract}
Springs are discharges from groundwater that form water flows which are important in the provision of ecosystem services, such as irrigation of forests, supply of water for human consumption and the habitat for the aquatic biota. In Brazil, areas of Atlantic Forest are gradually being replaced by eucalypt crops, commonly changing the composition of the springs substrate. The objective of this study was to verify if the granulometric composition of the spring sediment in forest areas differs from that of springs in areas planted with eucalyptus. The tested hypothesis was that springs in eucalypts areas have differences in particle size and a lower percentage of organic matter when compared to springs in forest areas. To do so, the sediment from 20 springs was collected, all belonging to the Paraíba do Sul river basin, located in the state of Minas Gerais, Brazil. It was possible to observe that springs in forest areas were associated with very coarse sand, while those in eucalyptus areas were associated with finer granulometry particles. Regarding the organic matter, no significant difference was observed between the two areas. The study emphasizes the importance of riparian vegetation to mitigate potential impacts of eucalyptus silviculture on the sediment of springs.
\end{abstract}

Keywords: Atlantic Forest; Silviculture; Riparian vegetation

\footnotetext{
Biólogo, Me., Doutorando do Departamento de Biodiversidade e Conservação da Natureza, Universidade Federal de Juiz de Fora, Rua José Lourenço Kelmer, s/n, Campus Universitário Bairro São Pedro, CEP 36036-900, Juiz de Fora (MG), Brasil. pedrobio2009@gmail.com (ORCID: 00000003-0623-0897)

II Bióloga, Ma., Pesquisadora do laboratório de Invertebrados Bentônicos, Universidade Federal de Juiz de Fora, Rua José Lourenço Kelmer, s/n, Campus Universitário Bairro São Pedro, CEP 36036-900, Juiz de Fora (MG), Brasil. sheila.sipeixoto@gmail.com (ORCID: 0000-0002-5190-9527)

III Engenheiro Sanitarista e Ambiental, Pesquisador do Núcleo de Análise Geo Ambiental, Universidade Federal de Juiz de Fora, Rua José Lourenço Kelmer, s/n, Campus Universitário, Bairro São Pedro, CEP 36036-900, Juiz de Fora (MG), Brasil. micael.machado@outlook.com (ORCID: 0000-00027698-0338)

IV Engenheiro Civil, Dr., Professor do Departamento de Transporte e Geotecnia, Universidade Federal de Juiz de Fora, Rua José Lourenço Kelmer, s/n, Campus Universitário, Bairro São Pedro, CEP 36036-900, Juiz de Fora (MG), Brasil. barra.rocha@engenharia.ufff.br (ORCID: 0000-0003-1321-158X). Biólogo, Dr., Professor do Departamento de Zoologia, Universidade Federal de Juiz de Fora, Rua José Lourenço Kelmer, s/n, Campus Universitário, Bairro São Pedro, CEP 36036-900, Juiz de Fora (MG), Brasil. gama.alves@ufff.edu (ORCID: 0000-0001-8392-2091)
} 


\section{Introdução}

O sedimento dos ecossistemas aquáticos continentais é formado por uma grande variedade de materiais orgânicos e inorgânicos de origem autóctone e alóctone (CALLISTO; ESTEVES, 1996). Sua composição e distribuição em um corpo d'água são determinadas em grande parte pela escala e conjuntura geológica (WARD, 1992), que pode ser modificada através da entrada de grande variedade de materiais orgânicos particulados (CARNEIRO et al., 2009). No entanto, a redução e/ou conversão das florestas naturais em monoculturas pode promover mudança na composição granulométrica do sedimento (HARON et al., 1998; GRAÇA et al., 2002), devido ao aumento na entrada de sedimentos superficiais do solo e redução na entrada de matéria orgânica particulada (HERNANI et al., 1999; SILVA et al., 2011).

Devido a sua capacidade de crescer em solos de baixa fertilidade, apresentar rápido crescimento e ampla aplicabilidade de sua madeira, espécies do gênero Eucalyptus representam atualmente grande parte das áreas plantadas no mundo (CAMARGO et al., 2004; PINTO et al., 2004). Minas Gerais está entre os estados brasileiros com maior área plantada com espécies desse gênero, sendo grande parte destinada à produção de carvão vegetal, celulose e lenha (ASSOCIAÇÃO BRASILEIRA DE PRODUTORES DE FLORESTAS PLANTADAS, 2011). A conversão de florestas nativas em cultivos mais homogêneos e espaçados como a do eucalipto pode reduzir consideravelmente a chegada da matéria orgânica oriunda da vegetação natural para os sistemas aquáticos (GRAÇA et al., 2002; LARRAÑAGA et al., 2009), assim como permitir a entrada de maior volume de sedimento fino para esses ambientes, alterando a composição granulométrica do sedimento (FRANÇA; MORENO; CALLISTO, 2006). Giam et al. (2015) verificaram em riachos tropicais na Indonésia, uma composição granulométrica mais grossa em riachos de mata nativa quando comparada com aqueles localizados em monocultura de palma.

Habitat de nascentes são ecossistemas de água-doce únicos, devido às condições relativamente constantes de suas características físico-químicas (GLAZIER, 1991; WILLIAMS; WILLIAMS; CAO, 1997). Além disso, são ambientes importantes para a prestação de serviço ecossistêmico (CANTONATI; BERTUZZI; SPITALE, 2007), como irrigação de florestas, fornecimento de água de qualidade para o consumo humano e para fauna e são habitat que abrigam grande diversidade de organismos aquáticos. No entanto, apesar de serem protegidas pela Lei Federal n. 12.651/12 (BRASIL, 2012), as nascentes estão sujeitas a fortes pressões antropogênicas, tendo sua qualidade comprometida. Estudo sobre a composição granulométrica em nascentes assume papel importante, uma vez que possibilita evidenciar diferenças fundamentais no sedimento desses pequenos ecossistemas em áreas plantadas com eucalipto e em áreas de floresta, cujos resultados podem servir de embasamento científico para a preservação e recuperação desses mananciais.

Nesse sentido, o presente estudo verificou se a composição granulométrica do sedimento de nascentes tropicais em áreas de floresta difere daquelas em áreas plantadas com eucalipto. Testou-se a hipótese inicial de que nascentes em áreas de eucalipto apresentam a composição granulométrica mais fina e menor porcentagem de matéria orgânica quando comparadas com nascentes em áreas de mata natural, dado que a silvicultura do eucalipto tende a reduzir a heterogeneidade do substrato das nascentes, devido ao acúmulo de frações mais finas do sedimento.

\section{Material e métodos}

\section{Área de estudo}

O estudo foi realizado em nascentes de quatro áreas pertencentes a sub-bacias do rio Paraíba do Sul, situadas no estado de Minas Gerais, Brasil: A ( $\left.21^{\circ} 37^{\prime} 33,12^{\prime \prime S ~ e ~} 43^{\circ} 16^{\prime} 53,67^{\prime} \mathrm{O}\right)$, B 
$\left(21^{\circ} 39^{\prime} 40,125^{\prime \prime} \mathrm{S}\right.$ e $\left.43^{\circ} 34^{\prime} 30,05^{\prime \prime O}\right), \mathrm{C}\left(21^{\circ} 53^{\prime} 38,4^{\prime \prime} \mathrm{S}\right.$ e $\left.43^{\circ} 36^{\prime} 47,9^{\prime \prime O}\right)$ e D ( $21^{\circ} 52^{\prime} 57,5^{\prime \prime S}$ e $\left.43^{\circ} 36^{\prime} 13,5^{\prime \prime O}\right)$ (Figura 1).

Figura 1 - Localização das áreas A, B, C e D e nascentes (identificadas por número após a letra da área), distribuídas em áreas de eucalipto e floresta nas sub-bacias hidrográficas do rio Paraíba do Sul, estado de Minas Gerais, Brasil

Figure 1 - Location of areas A, B, C and D and the springs (identified by number after area letter), distributed in areas of eucalyptus and forest in the sub-basins of Paraíba do Sulriver, Minas Gerais state, Brazil

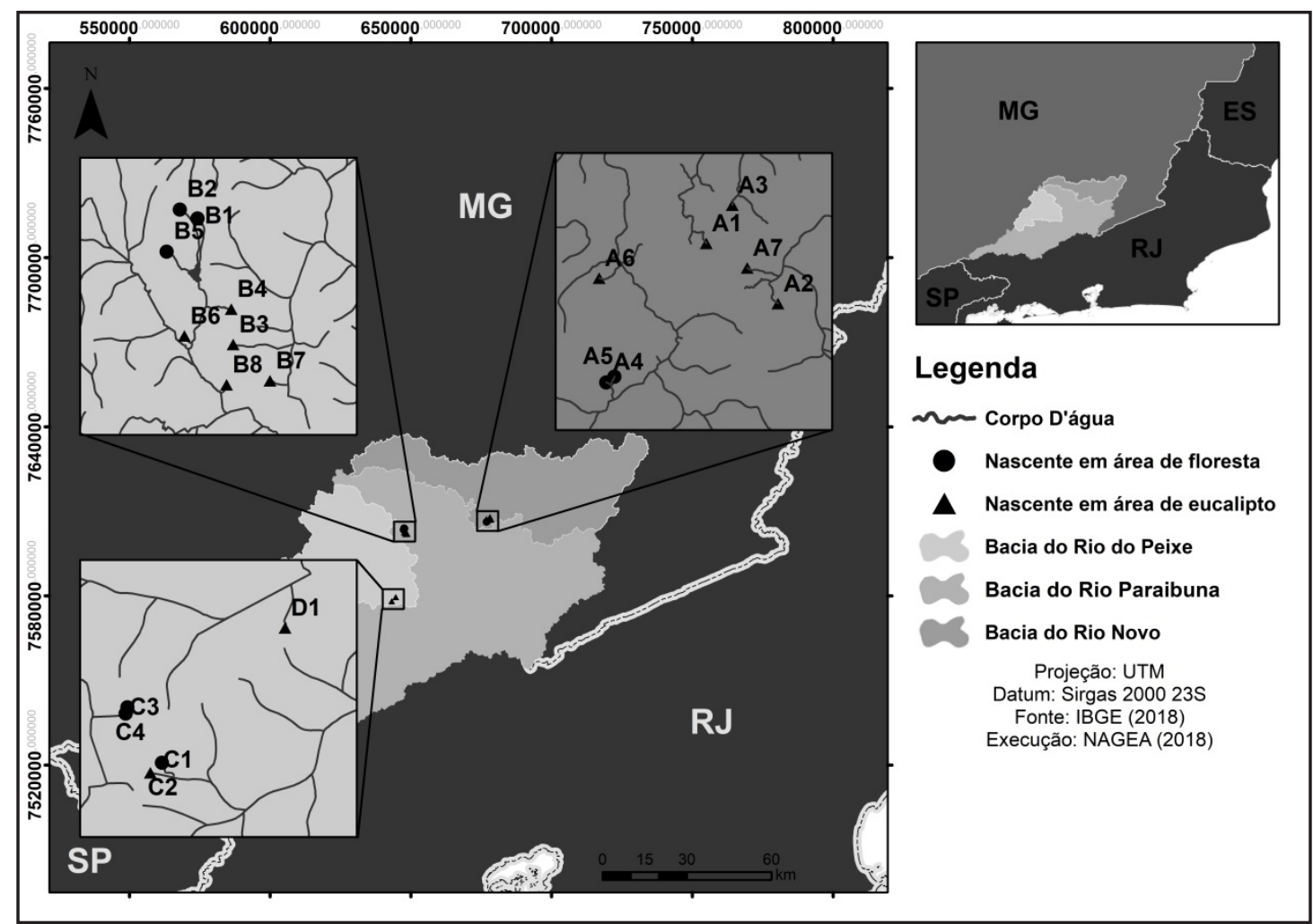

Fonte: Autores (2019)

O clima da região estudada é classificado como Cwa de acordo com a escala de Köppen (mesotérmico, com verão quente e chuvoso e inverno frio e seco), com temperatura média anual de $19^{\circ} \mathrm{C}$ e altitude em torno de $850 \mathrm{~m}$ (PREFEITURA DE JUIZ DE FORA, 2004). O tipo de solo predominante para a região estudada é classificado como Latossolo Vermelho-Amarelo (EMBRAPA, 1999).

\section{Amostragem}

Amostras de sedimentos superficiais $(0-10 \mathrm{~cm})$ foram coletadas na zona de extrusão de cada nascente com amostrador de mão (área $0,01 \mathrm{~m}^{2}$ e malha $250 \mu \mathrm{m}$ ). Um total de 20 nascentes perenes foi amostrado uma única vez entre junho, julho e agosto de 2017, correspondentes ao período de estiagem. A obtenção dos dados no período de estiagem do ano se deve ao fato de permitir a identificação de nascentes perenes, foco do presente estudo. As amostras foram armazenadas individualmente em sacos plásticos e levadas ao Laboratório de Invertebrados Bentônicos da Universidade Federal de Juiz de Fora (LIB/UFJF) no qual as análises foram realizadas. 
O dossel foi medido através de fotografias digitais distante $10 \mathrm{~cm}$ acima da superfície de cada nascente, câmera digital, com captação de imagem de tamanho $4000 \times 3000$ e 12 Megapixels. As imagens geradas foram convertidas em preto e branco e analisadas pelo software ImageJ (RASBAND, 2012). O resultado obtido foi um valor médio em pixels, que variou de 0 (cobertura total) a 255 pixels (entrada total de luz). Os valores obtidos foram convertidos em porcentagem.

\section{Caracterizações granulométricas}

Para caracterização granulométrica, $120 \mathrm{~g}$ de sedimento de cada amostra seca em temperatura ambiente foi separada e peneirada em agitador de peneira (SOLOTEST), por tempo padronizado de 30 minutos em um conjunto de peneiras de teste analítico (malha de $2 \mathrm{~mm}$ a 75 $\mu \mathrm{m})$ e classificadas em cinco frações: areia muito grossa $(1 \mathrm{~mm}<\mathrm{x}<2 \mathrm{~mm})$, areia grossa (500 $\mu \mathrm{m}<\mathrm{x}<1 \mathrm{~mm})$, areia média $(250 \mu \mathrm{m}<\mathrm{x}<500 \mu \mathrm{m})$, areia fina $(150 \mu \mathrm{m}<\mathrm{x}<250 \mu \mathrm{m})$, areia muito fina $(75 \mu \mathrm{m}<\mathrm{x}<150 \mu \mathrm{m})$ e silte/argila $(<75 \mu \mathrm{m})$ de acordo com o procedimento recomendado pela norma técnica ABNT NBR 7181 (1982). Cada fração de sedimento foi pesada em balança de precisão com $\pm 0,001 \mathrm{~g}$.

Parte do sedimento coletado $(3 \mathrm{~g})$ de cada amostra foi separada e incinerada em mufla a $550^{\circ} \mathrm{C}$ por 4 horas para determinação do teor de matéria orgânica através da diferença entre a massa das amostras antes e depois da queima.

\section{Análises dos dados}

Análise de Componentes Principais (APC) foi utilizada para ordenar as nascentes segundo frações granulométricas, matéria orgânica e cobertura vegetal. O número de componentes principais (CPs) foi determinado considerando autovalores maiores que os gerados pelo método de Broken Stick. As variáveis ambientais que mais contribuíram para a formação dos eixos foram selecionadas através da análise de correlação de Pearson $(\mathrm{r}>0.7)$.

O teste $t$ de Student para amostras independentes foi realizado para verificar se houve diferença significativa $(\mathrm{p}<0.05)$ na composição granulométrica, matéria orgânica e cobertura vegetal entre as nascentes em área de eucalipto e área de floresta. Com a finalidade de analisar a distribuição granulométrica entre as nascentes em área de eucalipto e área de floresta foi gerado um gráfico boxplot de Barchart.

As análises estatísticas foram executadas no software R (R CORE TEAM, 2016), com uso do pacote Vegan (OKSANEN et al., 2016).

\section{Resultados e discussão}

Os dois primeiros eixos da PCA explicaram 63\% da variação dos dados ambientais. Apesar da posição intermediária de parte das nascentes nas diferentes áreas, o primeiro eixo foi positivamente correlacionado com a areia grossa, areia média, areia fina, areia muito fina, silte e argila e nascentes em áreas plantadas com eucalipto. O segundo eixo foi positivamente correlacionado com areia muito grossa, cobertura vegetal e as nascentes em áreas de floresta (Figura 2).

O carreamento, a entrada e a deposição de sedimentos de menor fração granulométrica devido ao uso da terra estão entre os impactos mais importantes sobre os sistemas aquáticos em todo o mundo (WANTZEN, 2006), por causar redução da heterogeneidade de habitat (KRUPEK; FELSKI, 2006), levando à perda da diversidade biológica desses ambientes, incluindo nascentes. Os resultados deste trabalho evidenciam maior associação de substrato muito grosso e cobertura vegetal em áreas de floresta, enquanto as nascentes em áreas de eucalipto estiveram associadas às partículas de menor granulometria. Sistemas aquáticos podem sofrer o efeito 
da proximidade com as áreas plantadas com eucalipto e com seu manejo ambiental da área (SALGADO; MAGALHÃES JUNIOR, 2006). A presença de sedimentos de menor granulometria está associada à redução da vegetação ciliar (BRITO et al., 2009) e erosão do solo, o que pode causar assoreamento dos corpos d'água, provocando prejuízos e implicações ao agricultor e à biodiversidade local (KRUPEK; FELSKI, 2006). De acordo com Hammes (2002), o aumento na carga de sedimento fino nos corpos d'água pode provocar a obstrução das brânquias de peixes, e, conforme a natureza dos sedimentos carreados, altera a composição da fauna que habita o fundo de ambientes aquáticos.

Figura 2 - APC considerando as frações granulométricas, matéria orgânica e cobertura vegetal de nascentes em sub-bacias hidrográficas do rio Paraíba do Sul, sudeste do Brasil

Figure 2 - PCA considering the granulometric fractions, organic matter and vegetation cover of springs in Paraíba do Sul river basins, southeastern Brazil



Fonte: Autores (2019)

Em que: $\mathrm{AMG}=$ areia muito grossa; $\mathrm{AG}=$ areia grossa; $\mathrm{AM}=$ areia média; $\mathrm{AF}=$ areia fina; $A M F$ = areia muito fina; S_A = silte e argila; $M O$ = matéria orgânica; C.vegetal = cobertura vegetal.

Por outro lado, o predomínio do sedimento mais grosso em nascentes em áreas de floresta pode estar associado ao bom estado de conservação da vegetação natural do seu entorno, visto que a complexidade estrutural da vegetação pode tamponar os efeitos do uso do solo (FERREIRA-PERUQUETTI; FONSECA-GESSNER, 2003). França, Moreno e Callisto (2006), que estudaram a composição granulométrica e sua relação com a redução da heterogeneidade ambiental pelo uso e ocupação do solo do Rio da Velhas no estado de Minas Gerais, verificaram que as frações granulométricas mais grossas são predominantes nos ambientes classificados 
como conservados, enquanto que as frações mais finas são abundantes em trechos alterados. Os efeitos negativos da silvicultura sobre o substrato estão muitas vezes associados ao tipo de vegetação e ao manejo ambiental dessas áreas (WIESMEIER et al., 2009; KLUG et al., 2020). Nesse contexto, há evidências de que a preservação de espécies vegetais nativas dentro de sistemas agrários tenha papel fundamental na regulação dos processos hidrológicos e na preservação da biodiversidade local (ALTIERI, 1999). Esses resultados corroboram a hipótese inicial, que a silvicultura do eucalipto tende a reduzir a heterogeneidade ambiental, refletindo no afinamento da composição granulométrica, devido ao carreamento de partículas de menor tamanho como silte e argila para as nascentes.

Apesar da APC indicar associação entre o afinamento granulométrico e nascentes em áreas de eucalipto, os resultados do teste $t$ de Student (Tabela 1) indicaram que a areia grossa $(\mathrm{t}=2.82 ; \mathrm{p}<0.01$; ) foi a única variável significativamente afetada pelas plantações de eucalipto. Isso indica que a presença da vegetação ripária, no entorno de parte das nascentes estudadas em áreas de eucalipto, pode ter contribuído para a redução da entrada de material sedimentar fino (Figura 3). Esse resultado evidencia a importância de avaliar a relação das áreas plantadas com eucalipto e o sedimento em diferentes localidades, de modo a refletir o impacto ambiental do manejo da paisagem de diferentes áreas (RANZINI; LIMA, 2002). Segundo Resende et al. (2009), o isolamento de nascentes através do cercamento e a adequação das Áreas de Preservação Permanente (APP) para os 50 m exigidos no Código florestal brasileiro, Lei n. ${ }^{\circ}$ 12.651/12 (BRASIL, 2012), são ações indispensáveis para a conservação das nascentes perenes. A mata ciliar é de suma importância para a manutenção da qualidade dos corpos d'água (MARMONTEL; RODRIGUES, 2015), pois atua como barreira física retendo a entrada excessiva de sedimentos (BRITO et al., 2009), que podem ser lixiviados à nascente. Dessa forma, o manejo ambiental correto de áreas plantadas com eucalipto pode reduzir a entrada de sedimentos de menor granulometria, como silte e argila, reduzindo o impacto negativo sobre a qualidade ambiental das nascentes.

Tabela 1 - Teste $t$, valores médios e desvio padrão da composição granulométrica e cobertura vegetal de nascentes em área de eucalipto e área de floresta em sub-bacias hidrográficas do rio Paraíba do Sul, sudeste do Brasil

Table 1 - T-test, mean values and standard deviation of particle size and vegetation cover of springs in eucalyptus and forest area in watersheds of the Paraíba do Sulriver, southeastern Brazil

\begin{tabular}{lcccc}
\hline & \multicolumn{2}{c}{ Nascentes } & & Teste $t$ \\
\cline { 2 - 3 } AMG & Eucalipto & Floresta & p-valor \\
AG & $23.87 \pm 12.05$ & $53.85 \pm 24.64$ & 0.26 \\
AM & $23.03 \pm 14.24$ & $15.11 \pm 10.51$ & 0.01 \\
AF & $11.35 \pm 8.01$ & $15.75 \pm 10.51$ & 0.81 \\
AMF & $2.86 \pm 2.29$ & $2.83 \pm 2.43$ & 0.29 \\
S_A & $1.41 \pm 1.26$ & $0.86 \pm 0.87$ & 0.09 \\
MO & $0.59 \pm 0.72$ & $0.26 \pm 0.42$ & 0.13 \\
C.vegetal & $55.67 \pm 29.62$ & $52.65 \pm 18.65$ & \\
\hline
\end{tabular}

Fonte: Autores (2019)

Em que: $A M G=$ areia muito grossa; $A G=$ areia grossa; $A M=$ areia média; $A F=$ areia fina; $A M F=$ areia muito fina; S_A = silte e argila; $\mathrm{MO}=$ matéria orgânica C.vegetal = cobertura vegetal. 
Contrariamente a presente hipótese inicial, a matéria orgânica não esteve associada a uma área específica. Apesar do contraste estrutural com a vegetação natural, áreas plantadas com eucalipto mantêm a entrada de matéria orgânica vegetal nas nascentes que ocorrem nessas áreas. Além disso, a manutenção da vegetação ripária associada às áreas de eucalipto favorece o acúmulo de material orgânico particulado nos sistemas aquáticos (GRAÇA et al., 2002). Áreas plantadas com eucalipto contribuem de forma semelhante com a quantidade de componentes orgânicos em sistemas aquáticos (POZO et al., 1997). No entanto, a qualidade dessa matéria orgânica que entra nos corpos d'água pode ser de baixa qualidade, especialmente em nitrogênio e fósforo (COSTA; GAMA-RODRIGUES; CUNHA, 2005). Além disso, folhas de eucalipto possuem uma cutícula espessa e compostos secundários que retardam sua decomposição (MOLINERO; POZO, 2004). De acordo com Larrañaga et al. (2009), sistemas aquáticos em áreas de eucalipto estão sujeitos a uma redução qualitativa da entrada de matéria orgânica, uma das principais causas da redução da biodiversidade aquática nessas áreas. Portanto, a manutenção da vegetação ciliar pode ser uma das melhores formas de assegurar a qualidade da matéria orgânica e proteger o funcionamento dos ecossistemas de nascente.

Figura 3 - Gráfico de barras com o valor médio da composição granulométrica do substrato de nascentes em área de eucalipto e área de mata em sub-bacias hidrográficas do rio Paraíba do Sul, sudeste do Brasil

Figure 3 - Bar graph with the average value of the substrate particle size composition of springs in eucalyptus area and native forest area in Paraíba do Sul river basins, southeastern Brazil

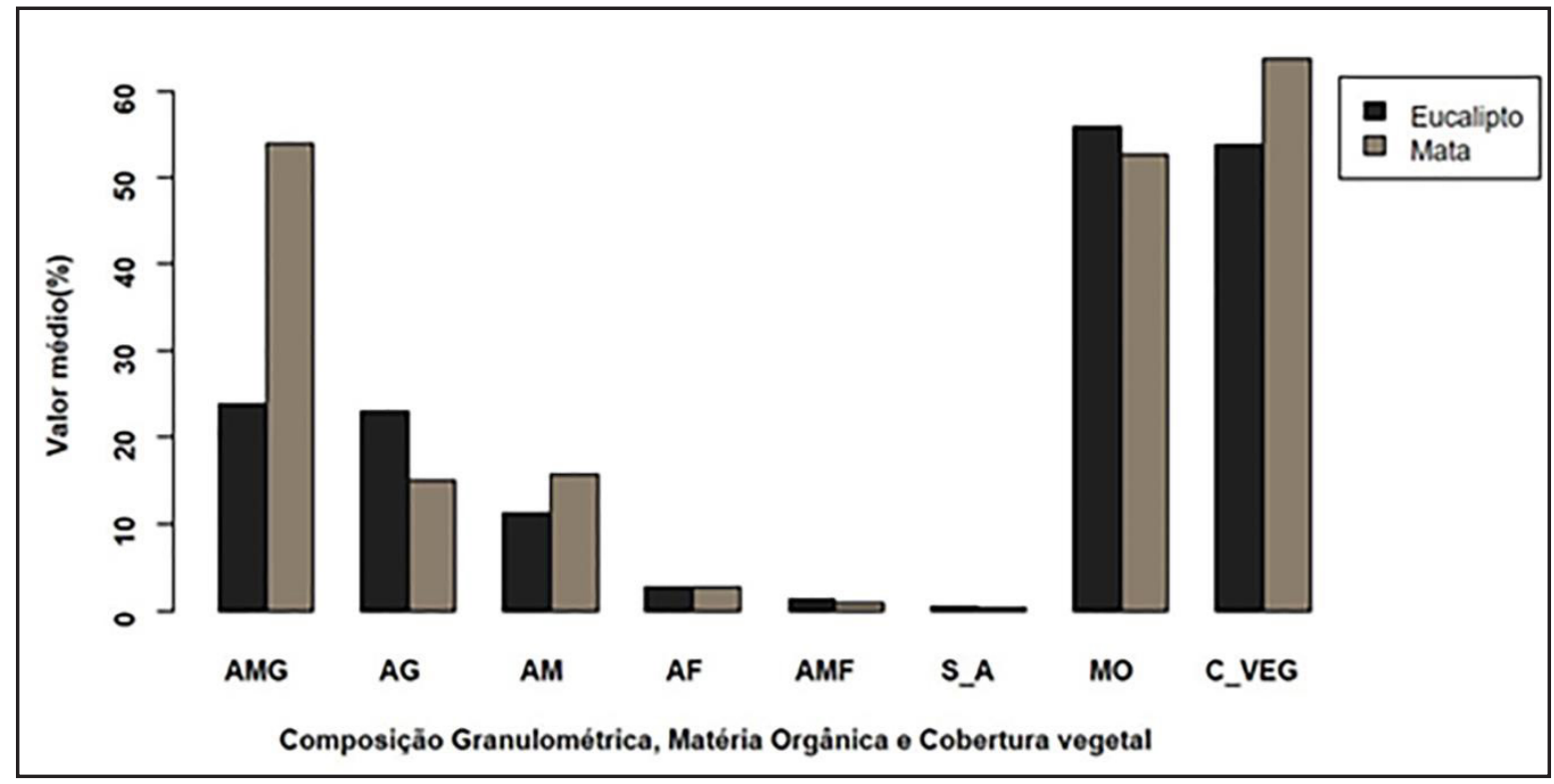

Fonte: Autores (2019)

Em que: $\mathrm{AMG}=$ areia muito grossa; $\mathrm{AG}=$ areia grossa; $\mathrm{AM}=$ areia média; $\mathrm{AF}=$ areia fina; $\mathrm{AMF}=$ areia muito fina; $S \_A$ = silte e argila; $M O$ = matéria orgânica; C.vegetal = cobertura vegetal. 


\section{Conclusão}

A partir dos dados deste estudo foi possível observar maior associação de fração de menor granulométrica em nascentes de áreas plantadas com eucalipto, corroborando a hipótese inicial. Por outro lado, a conservação da vegetação ripária em parte das nascentes em áreas de eucalipto, pode ter contribuído para a entrada de matéria orgânica e reduzido achegada de material sedimentar fino. Os resultados desta pesquisa enfatizam a necessidade de conservação da vegetação ripária, a fim de garantir as funções ecossistêmicas das nascentes, bem como o controle da qualidade de sua água.

\section{Agradecimentos}

Agradecemos ao Conselho Nacional de Desenvolvimento Científico e Tecnológico (CNPq) pelo financiamento (Processo: 304552 / 2015-1). PHMA estudante de Doutorado, MMMM estudante de graduação (iniciação científica) receberam bolsa da Universidade Federal de Juiz de Fora (UFJF, MG). SJP estudante de Mestrado recebeu bolsa da Coordenação de Aperfeiçoamento de Pessoal de Nível Superior(CAPES). Agradecemos também aos proprietários das fazendas pela oportunidade do estudo.

\section{Referências}

ALTIERI, M. A. The ecological role of biodiversity in agroecosystems. Agriculture, Ecosystems and Environment, [s. l.], n. 74, p. 19-31, 1999.

ASSOCIAÇÃO BRASILEIRA DE NORMAS TÉCNICAS. ABNT NBR 7182: Análise granulométrica de solos/método de ensaio. Rio de Janeiro, 1982.

ASSOCIAÇÃO BRASILEIRA DE PRODUTORES DE FLORESTAS PLANTADAS. Anuário estatístico da ABRAF: ano base 2010. Brasília, 2011. 130 p. Disponível em: http://www. bibliotecaflorestal.ufv.br/handle/123456789/3909?show=full. Acesso em: 13 jul. 2020.

BRASIL. Lei n.o 12.651, de 25 de maio de 2012. Diário Oficial da União: Seção 1, Brasília, DF, p. 1, 28 maio 2012. Disponível em: http://www.planalto.gov.br/ccivil_03/_ato2011-2014/2012/lei/ 112651.htm. Acesso em: 13 jul. 2020.

BRITO, R. N. R.et al. Características sedimentares fluviais associadas ao grau de preservação da mata ciliar - Rio Urumajó, nordeste paraense. Acta Amazônica, Manaus, n. 39, v. 1, p. 173-180, 2009.

CALISTO, M.; ESTEVES, F. A. Composição granulométrica do sedimento de um lago amazônico impactado por rejeito de bauxita e um lago natural (Pará, Brasil). Acta Limnologica Brasiliensia, Rio Claro, v. 8, p. 115-126, 1996.

CAMARGO, M. L. P. et al. Considerações sobre eficiência nutricional em Eucalyptus. Científica, Jaboticabal, v. 32, n. 2, p. 191-196, 2004.

CANTONATI, M.; BERTUZZI, E.; SPITALE, D. The spring habitat: biota and sampling methods. Monografie del Museo Tridentino Scienze Naturali, Trento, v. 4, p. 335-350, 2007. Disponível em:file://C:/Users/Usuario/Downloads/Cantonati_etal_2007_Summaries-MTSN-Monog4.pdf. Acesso em: 13 jul. 2018.

CARNEIRO, M. A. C. et al. Atributos físicos, químicos e biológicos de solo de cerrado sob diferentes sistemas de uso e manejo. Revista Brasileira de Ciência do Solo, Viçosa, MG, v. 33, 
p. $147-157,2009$.

COSTA, G. S.; GAMA-RODRIGUES, A. C.; CUNHA, G. M. Decomposição e liberação de nutrientes da serapilheira foliar em povoamentos de Eucalyptus grandis no Norte Fluminense. Revista Árvore, Viçosa, MG, v. 29, n. 9, p. 563-570, 2005.

EMBRAPA. Sistema brasileiro de classificação de solos. Brasília, 1999. 412 p.

FERREIRA-PERUQUETTI, P. S.; FONSECA-GESSNER, A. A. Comunidade de Odonata em áreas naturais de Cerrado e monocultura no nordeste do Estado de São Paulo, Brasil: relação entre o uso do solo e a riqueza faunística. Revista Brasileira de Zoologia, São Paulo, n. 20, v. 2, p. 219-1224, 2003.

FRANÇA, J.; MORENO. P.; CALLISTO, M. Importância da composição granulométrica para a comunidade bentônica e sua relação com o uso e ocupação do solo na bacia hidrográfica do rio das Velhas. In: ENCONTRO NACIONAL DE ENGENHARIA DE SEDIMENTOS, 7., 2006, Porto Alegre. Anais Eletrônicos [...]. Porto Alegre: ENES, 2006. Disponível em: http://labs.icb. ufmg.br/benthos/index_arquivos/pdfs_pagina/ArtigoAnaisPoa.pdf. Acesso em: 12 set. 2019.

GIAM, X. et al. Mitigating the impact of oil-palm monoculture on freshwater fishes in Southeast Asia. Conservation Biology, Boston, v. 29, n. 5, p. 1357-1367, 2015.

GLAZIER, D. S. The fauna of North American temperate cold springs: patterns and hypotheses. Freshwater Biology, Oxford, v. 26, p. 527-542, 1991.

GRAÇA, M. A. S. et al. Effects of Eucalyptus plantations on detritus, decomposers, and detritivores in streams. The Scientific World, Budapeste, n. 2, p. 1173-1185, 2002.

HAMMES, V. S. Erosão, um indicador de impacto ambiental. In: HAMMES, V. S. (org.). Educação ambiental para o desenvolvimento sustentável. Brasília: Embrapa Informação Tecnológica, 2002. v. 4. p. $40-43$,

HARON, K. et al. Dinâmica da biomassa microbiana e da matéria orgânica do solo em plantações de dendê (Elaeis guineensis jacq.), Oeste da Malásia. Soil Biology and Biochemistry, Elmsford, v. 30, n. 5, p. 547-552, 1998.

HERNANI, L. C. Sistemas de manejo de solo e perdas de nutrientes e matéria orgânica por erosão. Revista Brasileira de Ciência do Solo, Viçosa, MG, v. 23, n. 1, p. 145-154, 1999.

KLUG, I. et al. Atributos químicos do solo em plantios florestais em substituição à vegetação nativa em campos de altitude. Ciência Florestal, Santa Maria, v. 30, n. 2, p. 279-290, 2020. DOI: https://doi.org/10.5902/1980509818905.

KRUPEK, R. A.; FELSKI, F. Avaliação da Cobertura Ripária de Rios e Riachos da Bacia Hidrográfica do Rio das Pedras, Região Centro-Sul do Estado do Paraná. Revista Ciências Exatas e Naturais, Guarapuava, v. 8, n. 2, 2006.

LARRAÑAGA, A. et al. Impacts of Eucalyptus globules plantations on Atlantic streams: changes in invertebrate density and shredder traits. Fundamental and Applied Limnology/Archivfür Hydrobiologie, Stuttgart, v. 175, p. 151-160, 2009.

MARMONTEL, C. V.; RODRIGUES, V. A. Parâmetros indicativos para qualidade da água em nascentes com diferentes coberturas de terra e conservação da vegetação ciliar. Floresta e Ambiente, Seropédica, v. 22, n. 2, p. 171-181, 2015. DOI: doi.org/10.1590/2179-8087.082014.

MOLINERO, J.; POZO, J. Impact of a eucalyptus (Eucalyptus globulus Labill.) plantation on the nutrient content and dynamics of coarse particulate organic matter (CPOM) in a small stream. Hydrobiologia, The Hague, n. 528, p. 143-165, 2004.

OKSANEN, J. et al. Vegan: Community Ecology Package. R package Version 2.5-6. [S. l.: s. n.], 2019. Disponível em: https://CRAN.R-project.org/package=vegan. Acesso em: 13 jul. 2016. 
PINTO, R.et al. Coleópteros coletados com armadilhas luminosas em plantios de Eucalyptus urophylla na região amazônica brasileira. Ciência Florestal, Santa Maria, v. 14, p. 111-119, 2004.

POZO, E, J.et al. Inputs of particulate organic matter to streams with different riparian vegetation. Journal of The North American Benthological Society, [s. l.], n. 16, v. 3, p. 602-61, 1997.

PREFEITURA DE JUIZ DE FORA (MG). Plano diretor de desenvolvimento urbano de Juiz de Fora. Juiz de Fora: FUNALFA, 2004.

RANZINI, M.; LIMA, W. P. Comportamento hidrológico, balanço de nutrientes e perdas de solo em duas microbacias reflorestadas com Eucalyptus, no Vale do Paraíba, SP. Scientia Forestalis, Piracicaba, n. 61, p. 144-159, 2002.

RASBAND, W. S. ImageJ: Image Processing and Analysis in Java. [S. l.: s. n.], 2012. Disponível em: https://imagej.nih.gov/ij/download.html. Acesso em: 13 jul. 2020.

R CORE TEAM.R: a language and environment for statistical computing. Vienna: R Foundation for Statistical Computing, 2020. Disponível em: https://www.r-project.org/. Acesso em: 13 jul. 2016.

RESENDE, H. C. et al. Diagnóstico e ações de conservação e recuperação para as nascentes do córrego-feio, Patrocínio, MG. Bioscience Journal, Uberlândia, v. 25, n. 5, p. 112-119, 2009.

SAlGADO, A. A. R.; MAGALHÃES JÚNIOR, A. P. Impactos da silvicultura de eucalipto no aumento das taxas de turbidez das águas fluviais. Geografias, Belo Horizonte, n. 2, v. 1, p. 47-57, 2006.

SILVA, M. A. et al. Sistemas de manejo em plantios florestais de eucalipto e perdas de solo e água na região do Vale do Rio Doce, MG. Ciência Florestal, Santa Maria, v. 21, n. 4, p. 765-776, 2011.

WANTZEN, K. M. et al. Stream valley systems of the Brazilian Cerrado: impact assessment and conservation scheme. Aquatic Conservation: Marine and Freshwater Ecosystems, Chichester, v. 16, n. 7, p. 713-732, 2006.

WARD, J. V. Aquatic insect ecology: 1. Biology and Habitat. New York: Wiley, 1992. 438 p.

WIESMEIER, M. M. et al. Depletion of soil organic carbon and nitrogen under Pinus taeda plantations in Southern Brazilian grasslands (Campos). European Journal of Soil Science, Oxford, v. 60, n. 3, p. 347-359, 2009.

WILLIAMS, D. D.; WILLIAMS, N. E.; CAO, Y. Spatial differences in macroinvertebrate community structure in springs in southeastern Ontario in relation to their chemical and physical environments. Canadian Journal of Zoology, Ottawa, v. 75, p. 1404-1414, 1997. 